\title{
DESIGN OF SIERPINSKI CARPET FRACTAL MICROSTIP PATCH ANTENNA FOR WLAN APPLICATIONS
}

\author{
T. Divya Bharathi, N. Akshaya \\ Student, Department of ECE \\ Rajiv Gandhi College of Engineering Technology, \\ Puducherry, India.
}

\begin{abstract}
A Sierpinski Carpet fractal microstrip patch antenna has been designed for WLAN applications. A Sierpinski carpet is a simple fractal structure with self similar structures which improves the effectiveness of the patch length and enhance transmission capability of the antenna. The antenna design has a Patch and Ground plane (Copper) mounted on FR-Substre with quarter wave transformer feed. The dimensions of the Sierpinski carpet are $15.4 \times 13.6 \mathrm{~mm}^{2}$ which is a compact sized design, made using High Frequency Structure Simulator software. The simulation outputs are internally compared with different iterations implemented on the patch using Iterated Function System (IFS) and the variations are observed. The variations in operating frequency for the iterations are ranging from $4.8 \mathrm{GHz}$ to $4.95 \mathrm{GHz}$ which are used in WLAN applications. Thus, the Sierpinski Carpet structure provides improvements in the antenna parameters on raising scale of iteration such as $\mathrm{S11}$ from $\mathbf{- 2 2 . 8 6} \mathrm{dB}$ to 45.76 dB, average gain of $4.1 \mathrm{~dB}$ and Impedance Bandwidth of $31.25 \%$.
\end{abstract}

Keywords - FR-4, Patch, Antenna design, Sierpinski Carpet, WLAN.

\section{INTRODUCTION}

A microstrip antenna could be a variety of an antenna widely employed in telecommunication and they are fabricated using microstrip techniques on an electrical circuit board (PCB). It is also called as a printed antenna. A microstrip antenna consists of a patch that is of various shapes, a ground plane on the opposite side of the board and a substrate. The purpose of cutting a slot from the patch of an antenna is that it behaves as a load hence it will not be able to bring the input impedance almost like the characteristic impedance (e.g. $50 \mathrm{ohms}$ ) explained by Kiruthika et.al (2016). This improves the input impedance match and it leads to the development of S11 (S-parameter). S11 is understood because the return loss, or what proportion power is reflected from the transmitter to an antenna elaborated by Aravindraj et.al (2017). For patch slots the effect on resonant frequency shift is more pronounced than in ground plane slots. This shows the

\author{
Dr. K. Ayyappan \\ Professor, Department of ECE \\ Rajiv Gandhi College of Engineering Technology, \\ Puducherry, India.
}

greater reduction size due to patch slots as compared to ground plane slots. Bandwidth and gain has been found to be more affected by squeeze patch than by squeeze ground plane delivered by Rahman et.al (2019), Manas et.al (2019) and Vandana et.al (2019). The construction of the Sierpinski carpet begins with a rectangular patch given by Romeu et.al (2001), Mahesh et.al (2017) and Manish Gupta (2017). Square pieces are equally separated into nine parts and so the center square is removed from each. In several PCB applications FR4 epoxy glass substrates are the fabric of choice. It is relatively low cost and has outstanding mechanical properties which make it ideal for a wide range of applications for electronic components demonstrated by Guda (2019), Jayanthy et.al (2017), Alagumeenal et.al (2019) and Shuba Gupta (2017).

FR-4 is a laminate material with glass-reinforced epoxy. FR-4 glass epoxy can be a common and durable laminate grade high pressure thermostat. FR4 has zero absorption of water; FR-4 is most widely used as an electric insulator of significant mechanical power published by Aravinraj et.al (2017). In both dry and humid conditions, the fabric is understood to maintain its high mechanical values and electrical insulating properties. Usually, FR-4 epoxy systems incorporate a halogen to enable flammable properties. A quarter-wave transmission line provides a good impedance value. The operation is similar to stub; yet the shorting pims are required. The length and width of the antenna are adjusted for require impedance. HFSS has recent advancements in the EM antenna technology and reduced the complexity in the in terms. These analyses provide sensitivity, performance and marketing. It provides a three-dimensional structure enriched by Ayyappan et.al (2018). Mobile communication includes antennas which are lightweight, low-cost and low profile. Microstrip patch antenna fulfills all specifications, and antennas are designed for use in mobile communication systems. 


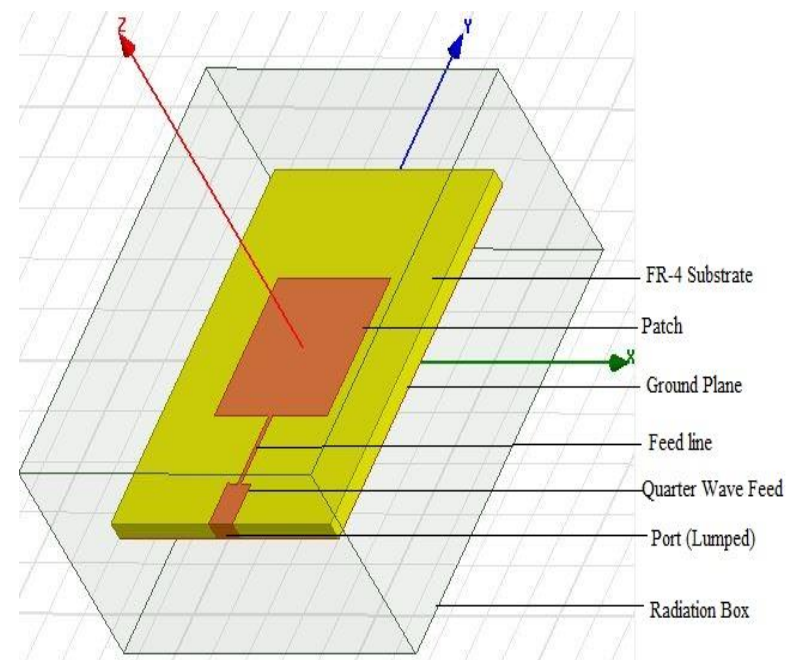

Fig. 1 Structure of Patch antenna for Quarter wave feed

Fig.1 shows the overall structure of patch antenna with Quarter wave feed. Hereby, the basic design procedure of MPA antenna's discussed by different authors are given from the fundamentals.

\section{ANTENNA StRUCTURE}

The design of microstrip patch antenna has three layers (i) patch (Copper); (ii) Substrate (FR-4) $\left(\varepsilon_{r}=4.4\right.$; $\left.\tan \delta=0.02\right)$; (iii) Ground Plane (Copper) with thickness 1.6.

\section{A. Sierpinski Carpet fractal structure}

The Sierpinski Carpet construction starts with a square. This square is divided into four pieces which are identical. The smallest square in the middle is far from the first bigger square.

Table. I Stages of Sierpinski Carpet fractal geometry

\begin{tabular}{|c|c|}
\hline Iterations & Dimensions \\
\hline $\mathbf{0}^{\text {th }}$ Iteration & None \\
\hline $\mathbf{1}^{\text {St }}$ Iteration & $3.6 \mathrm{~mm} \times 3.6 \mathrm{~mm}$ \\
\hline $\mathbf{2}^{\text {nd }}$ Iteration & $1.8 \mathrm{~mm} \times 1.8 \mathrm{~mm}$ \\
\hline $\mathbf{3}^{\text {rd }}$ Iteration & $0.9 \mathrm{~mm} \times 0.9 \mathrm{~mm}$ \\
\hline $4^{\text {th }}$ Iteration & $0.45 \mathrm{~mm} \times 0.45 \mathrm{~mm}$ \\
\hline
\end{tabular}

Table. I show the Stages of Sierpinski Carpet Fractal geometry. A pattern of Sierpinski Carpet is observed on repeating this cycle using Iterated Function System (IFS). The design of the microstrip Sierpinski carpet fractal antenna follows the approach of various considerations. It enhances the electrical area of the radiating element.
The geometry of the Sierpinski fractal iterations are shown in Fig. 2. On comparing each figure, the improvements in the increasing order of the fractal design can be observed.

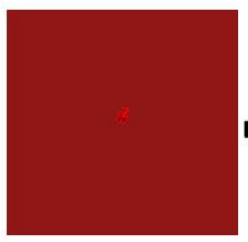

(0)

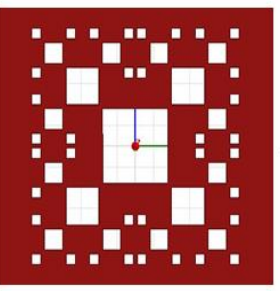

(4)

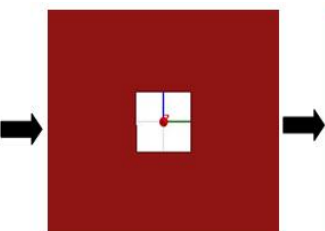

(1)

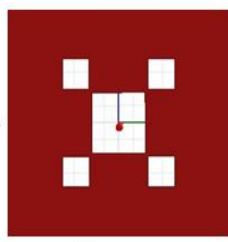

(2)
Fig. 2 Different iterations of Sierpinski Fractal structure

\section{B. Methodology and Design}

The methodology and the dimensions of the antenna follow the following formulae. Table. II lists the antenna dimensions and Fig. 3 shows the Sierpinski Carpet Fractal structure for all the fourth iteration.

Patch Width $(W)$ :

$W=\frac{C}{2 f_{r}} \sqrt{\frac{2}{\varepsilon_{r}+1}}$

where, $\dot{\varepsilon}_{r}$ - Dielectric constant

$$
\begin{gathered}
f_{r}-\text { Radiating Frequency } \\
c-\text { Velocity of light }
\end{gathered}
$$

Effective Dielectric Constant:

$$
\varepsilon_{\text {reff }}=\frac{\varepsilon_{r}+1}{2}+\frac{\varepsilon_{r}-1}{2}\left(1+\frac{12 h}{W}\right)^{-1 / 2}
$$

Patch Length Extension:

$$
\Delta L=0.412 h\left(\frac{\varepsilon_{r e f f}+0.3}{\varepsilon_{r e f f}-0.258}\right)\left(\frac{\frac{W}{h}+0.264}{\frac{W}{h}+0.8}\right)
$$

where, $h$-Height of the substrate Effective Patch Length:

$$
L_{e f f}=\frac{c}{2 f_{r} \sqrt{\varepsilon_{\text {reff }}}}
$$


Patch Length:

$$
L=L_{\text {eff }}-2 \Delta L
$$

Substrate Width or Ground plane width:

$$
W_{s}=W_{g}=6 h+W
$$

Substrate length or Ground Plane length:

$$
L_{s}=L_{g}=6 h+L
$$

\begin{tabular}{|c|c|c|}
\hline $\begin{array}{c}\text { Antenna } \\
\text { Part }\end{array}$ & $\begin{array}{c}\text { Design } \\
\text { (symbols) }\end{array}$ & Dimensions \\
\hline \multirow{3}{*}{ Substrate } & Length $\left(L_{s}\right)$ & $35 \mathrm{~mm}$ \\
\hline & Width $\left(W_{s}\right)$ & $30 \mathrm{~mm}$ \\
\hline & Height $(h)$ & $1.6 \mathrm{~mm}$ \\
\hline \multirow{3}{*}{ Patch } & Length $(L)$ & $13.6 \mathrm{~mm}$ \\
\hline & Width $(W)$ & $15.4 \mathrm{~mm}$ \\
\hline & Thickness $(t)$ & $0.04 \mathrm{~mm}$ \\
\hline \multirow{4}{*}{ Feed line } & $\mathrm{Z}_{\mathrm{L}}$ Length $\left(f_{l}\right)$ & $6.7 \mathrm{~mm}$ \\
\hline & $\mathbf{Z}_{\mathrm{L}}$ Width $\left(f_{w}\right)$ & $0.5 \mathrm{~mm}$ \\
\hline & $Z_{0}$ Length $\left(Z_{l}\right)$ & $4 \mathrm{~mm}$ \\
\hline & $Z_{0}$ Width $\left(Z_{w}\right)$ & $3.24 \mathrm{~mm}$ \\
\hline \multirow{2}{*}{$\begin{array}{l}\text { Ground } \\
\text { plane }\end{array}$} & Length $\left(L_{s}\right)$ & $35 \mathrm{~mm}$ \\
\hline & Width $\left(W_{s}\right)$ & $30 \mathrm{~mm}$ \\
\hline
\end{tabular}

Table. II Dimensions of antenna structure

\section{Substrate and Ground Plane}

In theory of antennas, a ground plane can be a large conductive surface relative to the wavelength, which is attached to the ground wire of the transmitter and is a reflective surface for radio waves. A ground plane in computer circuit boards can be a wide area of copper foil on the board which is connected to the ground terminal supply facility and is a return route for current from different components on the board.

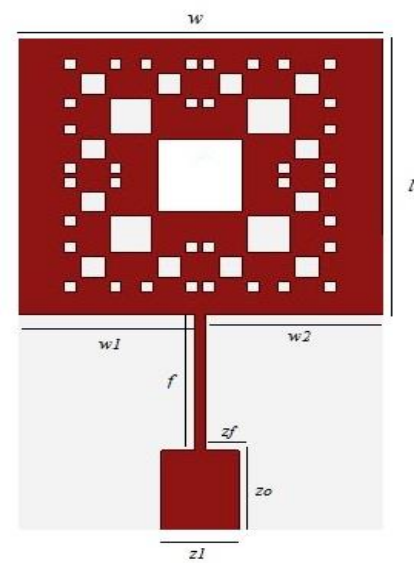

Fig. 3 Sierpinski Carpet structure with Quarter wave feed
Section II explains the structural geometry of the constructed Sierpinski fractal antenna.

\section{Simulation Results}

\section{A. Return Loss}

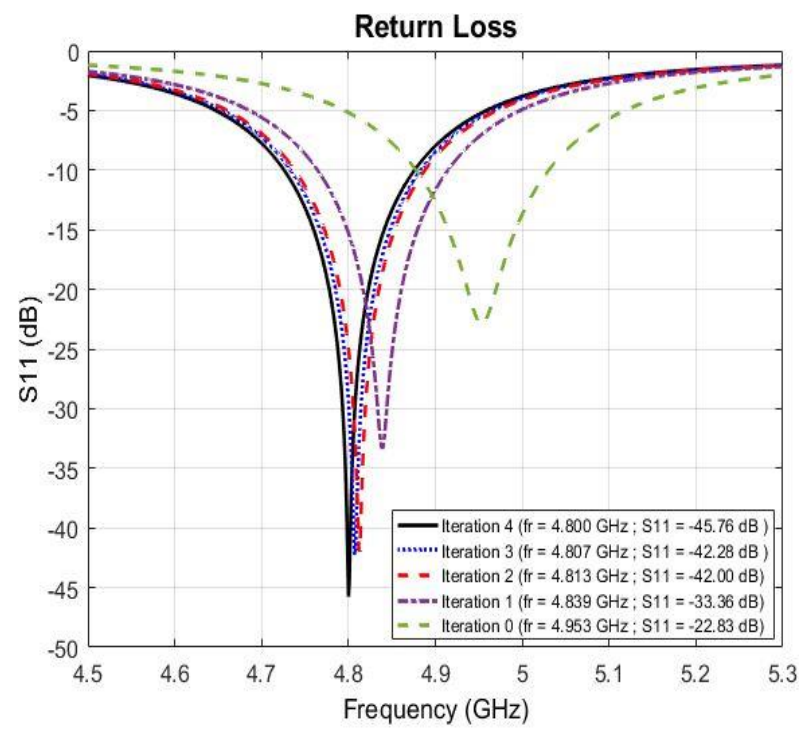

Fig. 4 Return Loss

The return loss may be a logarithmic ratio of the facility that fed to the antenna from the cable measured in $\mathrm{dB}$. The outputs of the fractal antenna are shown in Fig.4 and listed in Table. III.

Table. III Return Loss for different Iterations

\begin{tabular}{|c|c|c|}
\hline Iterations & $\begin{array}{c}\text { Radiating } \\
\text { frequency }\end{array}$ & $\begin{array}{c}\text { Return Loss } \\
(\mathbf{d B})\end{array}$ \\
\hline $0^{\text {th }}$ Iteration & $4.953 \mathrm{GHz}$ & -22.862 \\
\hline $1^{\text {St }}$ Iteration & $4.829 \mathrm{GHz}$ & -33.362 \\
\hline $2^{\text {nd }}$ Iteration & $4.813 \mathrm{GHz}$ & -42.003 \\
\hline $3^{\text {rd }}$ Iteration & $4.807 \mathrm{GHz}$ & -42.284 \\
\hline $4^{\text {th }}$ Iteration & $4.800 \mathrm{GHz}$ & -45.760 \\
\hline
\end{tabular}

\section{B. Bandwidth}

An antenna's bandwidth is that the frequency range over which the antenna is radiating properly. The antenna's bandwidth is that the difference of upper frequency and therefore the lower frequency at $-10 \mathrm{~dB}$ in $\mathrm{S}_{11}$. The Fig. 5 shows the Bandwidth assessments for iterations of fractal structure. 


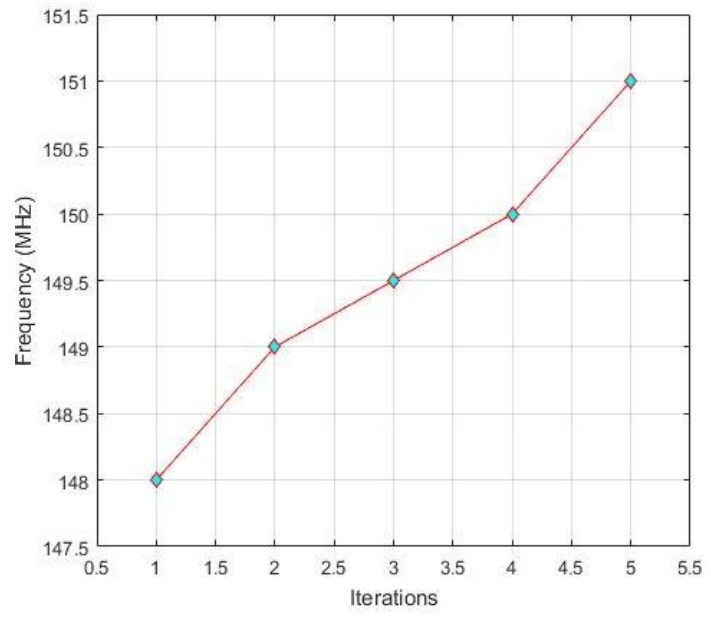

Fig.5Bandwidth

\section{VSWR}

A measure of transmission line perfection is denoted by VSWR and Fig. 6 shows the VSWR. It also shows how well the antenna is impedance matched with the TM line of different iterations in the Fractal antenna.

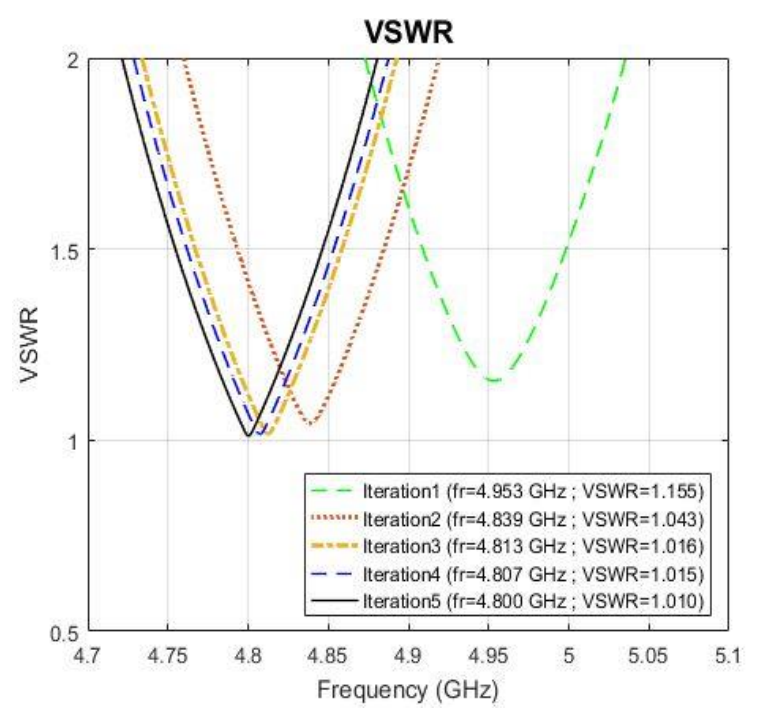

Fig. 6 VSWR

\section{Gain and Directivity}

The capability of the antenna to radiate in all the directions with peak power is called gain. The density of power antenna radiates in a particular directionFig. 7 and Fig. 8 represent the Gain and Directivity of the fractal antenna iterations wise.

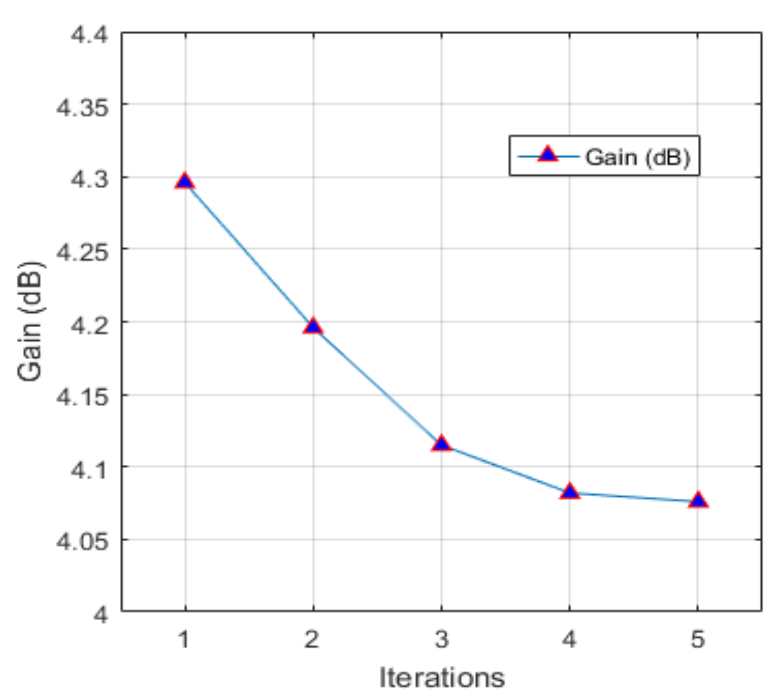

Fig. 7 Gain

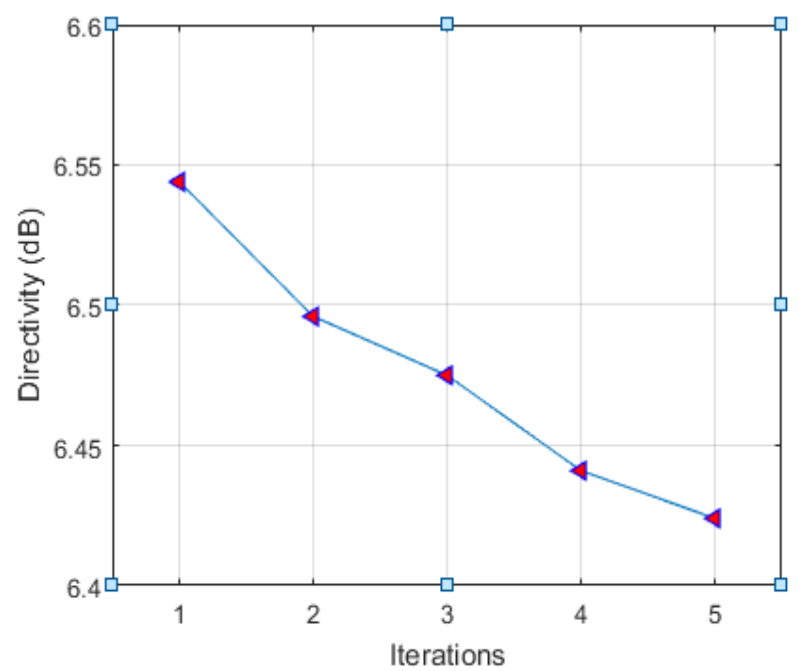

Fig. 8 Directivity

There are four iterations made using the Sierpinski fractal structure on HFSS platform. The zeroth iteration is a simple plane patch antenna with square shape is designed for 4.95 GHz. In First iteration, a square slot $(3.6 \mathrm{~mm} \times 3.6 \mathrm{~mm})$ is made on the patch. Then, the antenna started radiating at 4.829 $\mathrm{GHz}$. In second iteration, four square slots $\left(1.8 \times 1.8 \mathrm{~mm}^{2}\right)$ etched on the same antenna and it commences to radiate at $4.831 \mathrm{GHz}$. In third iteration, a $0.9 \times 0.9 \mathrm{~mm}^{2}$ square is made on the antenna which deals the antenna to radiate at 4.807 $\mathrm{GHz}$. In iteration four, a square of size $0.45 \times 0.45 \mathrm{~mm}^{2}$ is designed to produce an optimized frequency of $4.8 \mathrm{GHz}$ which is known as the operating frequency of the antenna. So, the 


\section{International Journal of Engineering Applied Sciences and Technology, 2020 \\ Vol. 5, Issue 2, ISSN No. 2455-2143, Pages 402-407 \\ Published Online June 2020 in IJEAST (http://www.ijeast.com)}

fractal structure obtained different simulation output at different structure which are listed in Table. IV.

Table. IV Output for Recursive Square Fractal antenna

\begin{tabular}{|c|c|c|c|c|}
\hline \multirow{2}{*}{ Iterations } & \multicolumn{4}{|c|}{ Parameters } \\
\cline { 2 - 5 } & $\begin{array}{c}\text { Return } \\
\text { loss (dB) }\end{array}$ & $\begin{array}{c}\text { Bandwidth } \\
(\mathrm{MHz})\end{array}$ & $\begin{array}{c}\text { Gain } \\
(\mathrm{dBm})\end{array}$ & $\begin{array}{c}\text { Directivity } \\
(\mathrm{dBm})\end{array}$ \\
\hline $\begin{array}{c}\text { Iteration 0 } \\
\text { (fr=4.953 } \\
\text { GHz) }\end{array}$ & -22.862 & 148 & 4.296 & 6.544 \\
\hline $\begin{array}{c}\text { Iteration 1 } \\
\text { (fr=4.829 } \\
\text { GHz) }\end{array}$ & -33.362 & 149 & 4.196 & 6.496 \\
\hline $\begin{array}{c}\text { Iteration 2 } \\
\text { (fr=4.813 }\end{array}$ & -42.003 & 149.5 & 4.115 & 6.475 \\
\hline $\begin{array}{c}\text { GHz) } \\
\text { Iteration 3 } \\
\text { (fr=4.807 }\end{array}$ & -42.284 & 150 & 4.082 & 6.441 \\
\hline $\begin{array}{c}\text { GHz) } \\
\text { Iteration 4 } \\
\text { (fr=4.800 } \\
\text { GHz) }\end{array}$ & -45.760 & 151 & 4.076 & 6.424 \\
\hline
\end{tabular}

\section{CONCLUSION}

A Sierpinski carpet structure is taken for the analysis, the structure of the fractal design is planned to construct with four different iteration levels. The square slots that to be inserted to the antenna are $3.6 \times 3.6 \mathrm{~mm}^{2}, 1.8 \times 1.8 \mathrm{~mm}^{2}, 0.9 \times 0.9 \mathrm{~mm}^{2}$, $0.45 \times 0.45 \mathrm{~mm}^{2}$. Each of the slots will produce a different optimized output using Iterated Function System (IFS). The proposed antenna has a radiating element (Patch), Dielectric material (FR-4 Substrate) and Ground Plane which is fed using a quarter wave transmission lines. The output has been analysed for four different iterations using HFSS platform. On differing each fractal iterations of radiating element, the simulation parameters such as radiating frequency, VSWR, Gain, Bandwidth, Directivity, and Return loss are compared each other. The radiating frequencies four iterations are 4.95 $\mathrm{GHz}, 4.82 \mathrm{GHz}, 4.81 \mathrm{GHz}$ and $4.8 \mathrm{GHz}$ with a better improving order results. Thus, the proposed Sierpinski Carpet fractal structure provides a improved S11 outputs from -22.86 $\mathrm{dB}$ to $-45.76 \mathrm{~dB}$, average gain of $4.1 \mathrm{~dB}$ and Impedance Bandwidth of $31.25 \%$.

\section{ACKNOWLEDGEMENT}

We (Authors) acknowledge Mr. E. Aravindraj, Research scholar, Department of Electronics and Communication Engineering Pondicherry Engineering College for spending his time with us and providing suggestions for the successful completion of the project.

\section{REFERENCE}

[1] Kiruthika.R. and Dr.Shanmuganantham.T.(2016) "Comparison of Different Shapes in Microstrip Patch Antenna for X-band Applications", International Conference on Emerging Technological Trends, DOI: 10.1109/ICETT.2016.7873722 .

[2] Aravindraj. E. and Dr. K. Ayyappan, (2017) "Design of Slotted H-Shaped Patch Antenna for $2.4 \mathrm{GHz}$ WLAN Applications", International Conference on Computer Communication and Informatics, pp 1-5.

[3] Rahman.M.M., Islam.M.R. and Faisal.T.M. (2019)“A Compact Design and Analysis of A Fractal Microstrip Antenna For Ultra Wideband Applications", American Journal of Engineering Research, 8 (10), pp 45-49.

[4] Manas Ranjan Jena., Guru Prasad Mishra., Amiya BhusanaSahoo., B.B.Mangaraj. (2019) "Fractal Geometry and Its Application to Antenna Designs", International Journal of Engineering and Advanced Technology, 9(1), pp 3726-3743.

[5] Vandana G. Sawant., Aruna V, AnushaIyer., Diksha P., Deepthi S. (2019) "Design Of High Gain Fractal Antenna", International Journal of Research and Analytical Reviews, 6(1), pp 88-94.

[6] Romeu.J., Solar. J. (2001)" Generalized Sierpinski fractal multiband antenna", IEEE Transactions on Antennas and Propagation, 49(8), pp 1237-1239.

[7] Mahesh S Mathpati., Dr. Md. Bakhar Dhere. (2017) "Design and Simulation of Sierpinski Fractal Antenna Array", International Conference on Energy Communication Data Analytics and Soft Computing. pp $2514-2518$.

[8] Manisha Gupta.and Vinita Mathur. (2017) "Sierpinski fractal antenna for internet of things applications", International Conference on Recent Trends in Engineering and Material Sciences, pp 10298- 10303.

[9] Gudla Ramalakshmi. (2019) "Performance Characteristics of Modified Sierpinski Fractal Asntenna for Multiband Applications", International Journal of Recent Technology and Engineering, 8(2), pp 2194-2299.

[10] Jayanthy. T. and Rajeswari.D. (2017) "Design and Analysis of Hexagon Microstrip Patch Sierpinski Carpet Antenna", 2(2) pp 49-53.

[11] Alagumeenal.Pl, and Sindhujha.R. (2019) "Design of Sierpinski Fractal Monopole Antenna", International 
Journal of Innovative Research in Computer and Communication Engineering, 7(2), pp 690-695.

[12] Shubha Gupta. and Poonam Kshirsagar. (2017) "Sierpinski fractal inspired inverted pyramidal DRA for wide band applications", 38(2) pp 103-112.

[13] Aravindraj.E., Ayyappan.K. and Kumar.R.(2017) "Performance Analysis Of Rectangular MPA Using Different Substrate Materials For WLAN Application", ICTACT Journal on Communication Technology, 8(1), pp 1447-1452.

[14] Aravindraj.E., Kannan,.A. and Ayyappan.K, (2018) "Performance of Rectangular Microstrip Patch Antenna in Two Different Design Tools - A Comparative Study", International Journal of Scientific Research in Science, Engineering and Technology, 5(3), pp 13-21. 